\title{
First Aid Training: An Appraisal. The Soldier's Longest Journey
}

\author{
Maj T O Jefferson* \\ MSc, MRCGP, MFPHM, DRCOG, DTM\&H, RAMC \\ RAMC Training Centre, Keogh Barracks, Ash Vale, Hants GU12 5RO
}

SUMMARY: A two part study was carried out to identify the most cost-effective way of enhancing first aid in the British Army. There is a lack of co-ordination between a variety of training programmes for paramedical non-RAMC personnel.

Questionnaires were used to ascertain the views of users and experts were asked their views on the requirement for first aid at point of wounding on the battlefield. Skills needed in addition to those currently taught to all soldiers were indentified. These include the setting up of intravenous infusions, administration of analgesia and antibiotics and the recognition and treatment of battleshock.

\section{Introduction}

The 1982 Falklands Campaign re-taught the Army that treatment and evacuation of wounded, especially in the middle of a battle, may be a lengthy affair. This lesson had been forgotten in the years following the Second World War. During the attack on DarwinGoose Green in May 1982 some severely wounded members of the Parachute Regiment lay for hours where they had fallen until the ebb of battle allowed their comrades to come to their rescue. The delay in attending and evacuating the wounded led the Battalion doctor to describe the trip from point of wounding to medical care as "the soldier's longest journey" (S J Hughes, personal communication). Another medical officer, attached to the Scots Guards, discovered during the battle for Mount Tumbledown that the terrain, as well as the tactical situation, was hindering casualty treatment and evacuation.

He summed up the problems thus: "Stretcher parties attempting to evacuate came under fire and we received more casualties. Evacuation became impossible. . . . in these conditions if you don't receive, at point of wounding, first aid which is satisfactory you may perish." (A Warsap, personal communication).

The expectation of a prompt and efficient response to the needs of a wounded comrade is considered by all commanders to be a vital sustainer of morale and fighting spirit(1). The need to enhance survival on the battlefield requires the provision of sufficient first aid expertise at the frontline to sustain the life of a casualty until evacuation to a dedicated medical facility is possible. To meet this need the Regular Army currently trains all personnel yearly in basic first aid; the teaching is carried out by qualified Unit First Aid Instructors (UFAIs) to standards laid down in Army Training Directive 5 (ATD 5)(2) (Table 1).

Additionally each major unit has its own integral medical support and provision of first aid. This is centred around the Regimental Medical Officer (RMO) and a number of Regimental Medical Assistants (RMAs) who man the peacetime Battalion Medical Centre and the wartime Regimental Aid Post (RAP). Five armoured tracked ambulances evacuate all casualties from the front line to the RAP. From the RAP transport external to the Battalion will take the wounded to the second line medical facility. Each Company is allocated a small quota of RMAs who in wartime staff a Company Aid Post (CAP) which is a scaled down version (its kit fills a satchel) of a RAP without the medical officer. RMAs are in most cases full-time medics who progress through three classes of employment, from class 3 , the most junior and requiring supervision, to class 1 , the most experienced. RMA training commences with a 5 week course for RMA 3 and finishes with a 3 week course for upgrading from RMA 2 to 1 at the RAMC Training Centre. Some units also run first aid cadres which are loosely based on ATD 5. There is a perception that the present range of training programmes has not been evaluated, and that effectiveness and efficiency in teaching the necessary skills is uncertain.

\section{Table 1}

The main first aid subjects covered in Army Training Directive 5. These are taught to all adult ranks in the Army and refreshed every year.

The Aims and Principles of first aid Improvisation in casualty handling Airway management

Dealing with an unconscious casualty

Exhaled air resuscitation

External Cardiac Compression

Arrest of haemorrhage

Support an arm

Splint a leg

Recognition and treatment of fractures

Burns

Recognition and treatment of shock

Chest injuries

Abdominal injuries

Morphine administration 
A study was designed with the aim of identifying the most efficient way of enhancing Army first aid training for front line soldiers. The objectives of this part of the study were:

a. To formulate an operational requirement for first aid training.

b. To formulate a training requirement to match the operational requirement.

In the second part the efficiency of alternative training programmes is examined.

\section{Method}

The ideal study design would have been to test one first aid training programme against the other in a Randomised Control Trial (RCT). This is clearly not feasible. An alternative approach when a RCT is inappropriate is the use of an expert panel(3).

To define the first aid requirement a two phase opinion survey was carried out. In the first phase the views of users were sought using an anonymous questionnaire. A series of questions was put to 222 officers in the rank of Lieutenant or Captain from all Arms of the British Army. These were attending two consecutive Army Junior Staff College courses. They were a representative cross-section of the junior officer cadre in the Army and all were holding or had held junior command positions within their units. There is no prima facie reason to believe that their roles and attitudes were any different from the remainder of Army officers of equal seniority.

The questions were:

1. Do you believe that there is a requirement at first line for a first aider who is trained to higher standard than ATD 5?

2. Have you ever sent a soldier on a Regimental Medical Assistant Class 3 (RMA) Course?

3. If so why did you send him or her on the course?

4. What do you think of the regimental Medical Assistant (RMA) RAMC-trained system? (Please use the back of this sheet for any extra comments).

Interviews would have enabled more in depth analysis, but in order to achieve maximum coverage a questionnaire was the quickest and cheapest tool available(4). In the second phase, the anonymous views of the users were put during the course of interviews to a panel of six experts in the rank-range Corporal to Colonel in order to obtain their views on the requirement of first aid on the battlefield.

The panel consisted of 4 medically qualified experts and one non medically qualified officer who had held command positions in war. The sixth member of the panel was a RAMC Corporal who was attached to one of the units which took part in most of the land battles of the Falklands War. Interviews were thought to be more appropriate in dealing with delicate and complicated issues such as peoples' experiences of injuries in war time and training programmes.

\section{Results}

The first topic in the questionnaire was the respondent's opinion on the requirement for first aid $\Omega$ knowledge to standards beyond those taught in ATD 5. 응

Two hundred and nine officers $(94 \%)$ thought that the ATD 5 syllabus, although good, did not include the treatment of some acute problems. Several officers $\stackrel{?}{+}$ specifically mentioned the absence of treatment of blood loss and shock by fluid replacement. One officer had no음 views on the matter and $12(5 \%)$ thought ATD sufficient $\frac{\bar{T}}{\vec{D}}$ to enable soldiers to carry out effective first aid at firsta. line. The officers were then asked whether they had ever@ nominated soldiers to attend RMA courses and if sowhy.

One hundred and fifty three officers $(69 \%)$ had sent $\vec{\omega}$ one or more of their soldiers on a RMA course during the previous three years. Eighty $(52 \%)$ had nominated@ one or more soldiers to improve first aid knowledge or in order to have "a qualified first aider" in their unit, $44 \stackrel{4}{\omega}$ $(29 \%)$ because their unit's standing orders required a quota of qualified RMAs, $14(9 \%)$ because there was a으. vacancy on the course which had been assigned to their' unit, $9(6 \%)$ so that the "qualified RMA 3 could then? instruct first aid to the other members of the platoon", $5(3 \%)$ so the soldier could start a career in the Battalio Medical Centre, and 1 could not remember.

The officers were then asked their views on the current system of first aid training at Battalion level Many expressed the view that there were not enougs vacancies for soldiers of their units to attend RMg $\Theta$ courses. These were generally regarded as one step \&. from ATD 5 in expertise.

A typical comment on the RMA system was: "It is nat very good. We need combat medics and what we get is base rat pill pushers who have little or no experience of patching people up."

In summary, the general consensus was that ATD $5 \stackrel{\vec{z}}{\vec{z}}$ does not cover all eventualities at first line. In particular, 3 the absence of fluid replacement was felt to be an important omission. The officers questioned and inter viewed thought there was a need for a more competent first aider. Some identified this individual as the RMA, others as their own unit trained first aiders. Of the officers who had nominated soldiers for a RMA course the majority had done so to enhance first aid knowledge and all complained of the fact that there were insufficient vacancies on such courses.

Six experts were asked for their opinions on the views of the Junior Staff College Officers.

The original intention of using unstructured 3 interviews with no feed back from the other experts waso justified as some experts exhibited signs of post $\supset$ traumatic stress syndrome when recalling their wartime? experiences. Three panel members indicated that they would have been reluctant to have participated in $\mathrm{a}^{\mathrm{G}}$ potentially stressful consensus panel.

All experts agreed with the requirement for an N enhancement of first aid capability at first line. The ATDE . 
5 syllabus on its own was thought to be insufficient. All agreed that at least one man per 8 man section and ideally one man in four should be trained above ATD 5 standard.

Additional skills needed, termed by one panel member "extended", include:

- intravenous fluid replacement

- the use of drugs in shock with special reference to antibiotics and the prevention of infection

- documentation skills, enough to record basic information on the nature of the treatment administered

- the recognition and treatment of battleshock

- basic prevention, treatment and recognition of diseases caused by environmental extremes.

All panel members felt that the requirement was to deliver first aid in order to sustain life on the battlefield for a period of between 6 and 8 hours. The ability to sustain life for a longer period, although desirable, was thought impracticable because of the limited supplies of equipment carried by the infantryman.

When asked their opinion of the RMA system all experts were of the opinion that RMAs are not meant to be dedicated first aiders on the front line. This is because of their training (which encompasses clinical and clerical skills as well as extended first aid) as well as their scarcity in any unit. Five experts deplored the unsupervised use of RMAs 3 in sub units as only RMAs class 1 are meant to work without supervision, while two pointed out that the employment of RMAs in sub units without refresher training would lead to a swift decay of their skills as they would have no clinical duties in peacetime.

One panel member, the infantry commander, expressed doubt that RMAs trained in peacetime are able to fulfil a role on the battle-line. He appeared unclear as to whether RMAs should be supervised according to their employment class. All panel members agreed that the first line medic should be able to sustain life for an extended period. Such a capabinity as beyond that of the ATD 5 trained man. ATD 5 standard first aid was thought to be the foundation upon which all subsequent training must be based.

Two panel members suggested an analysis of the current RMA training requirements as they thought the number trained yearly far in excess of the number of RMAs required Army wide. This will be examined in the second part of the study.

\section{Discussion}

Cain and Schwartz(5) asked whether, in the modern high tech battlefield there is still a place for self aid or buddy aid. Reviewing the evidence from recent conflicts they looked at the percentage of casualties who survived or died from wounds with arterial bleeding. In one series of 277 casualties killed in action they found $106(38 \%)$ who had bled to death from wounds which could have been controlled by first aid measures alone. They also noted that during the Israeli invasion of Lebanon many cases of first aid had been self-administered, usually successfully, thereby freeing the rest of the unit to get on with fighting the battle. Cain and Schwartz concluded that the requirement for self or buddy aid is present and its importance is enhanced by the intensity of modern warfare where prompt intervention by dedicated medics is unlikely.

The problem of the need for first aid at the point of wounding has been addressed by the US Army with the "Combat Life Saver" programme as described by Fogarty and others(6). This programme was started in 1983 in two Armoured Divisions and consists of a refresher phase for the 17 skills taught at basic soldier level in the US Army and an additional 8 skills taught by the specially trained Combat Life Saver instructors. The 17 basic skills are the same as in the British Army's ATD 5 (Table 1) plus a knowledge of heat injuries and the application of medical skills while wearing chemical proof clothing and a respirator. The additional 8 skills are:

- protect yourself against heat

- practise personal hygiene to maintain fitness

- protect yourself against diarrhoea and dysentery

- protect yourself against biting insects

- protect yourself against cold and give first aid for frostbite

- initiate and maintain an intravenous infusion

- transportation of the wounded soldier

- recognise and react to a combat stress casualty.

Approximately $75 \%$ of the vehicles of the two Divisions now have a crew member capable of delivering more sophisticated first aid than the average soldier.

The Combat Life Saver was introduced as a response to mounting concern about the importance of the quality and appropriateness of the first aid provided by the wounded soldier's buddy within the US Army after analysis of the operation of the Israeli Defence Force in Lebanon in 1983. In this conflict the importance of prompt first aid at the point of wounding was emphasised by the scarcity of dedicated medics(6).

Parker defined the stark contrast between the ideal and the real standard of care on the battlefield(7). The former is embodied in prompt evacuation by air and instant attention to the casualty's every need, the latter in long delays under fire and inadequate first aid. Parker's solution involves less reliance on the dedicated first line medical assets and more buddy aid. Hence better training for the average infantryman is required.

The literature providing qualitative and historical evidence for extended skills in first aid at first line appears overwhelming. There is widespread agreement among the armed forces of many countries about the need for first aid at point of injury, although it is based on experience gained in different theatres of war (Vietnam, Lebanon, the Falklands). This confirms the validity of the views expressed in our users' survey. The realisation of an operational need for extended first aid at point of wounding is not new but in peacetime armies with higher manpower turnover, lessons learnt in the 
heat of battle tend to be forgotten easily. The opinion survey carried out in this study suggests that this need is recognised by a large proportion of those interviewed and, in the absence of a suitable training programme, there seems to be a tendency by all units to regard the RMA as a suitable alternative.

In the second part of this study we shall analyse the training programmes which the Army currently offers, match them to the operational requirement and identify the most efficient way of providing training to match the operational requirement.

\section{Conclusions}

A clear requirement has been identified for extended first aid skills at first line in addition to those taught to all soldiers in ATD 5. They are the ability to set up intravenous infusions, administer pain killing and antibiotic injections, knowledge of conditions due to environmental extremes, basic documentation and the recognition and treatment of battleshock on the battlefield. Ideally, one man in every four should have such skills.

\section{Acknowledgements}

The author would like to thank the many people who provided advice and information, especially the sin panel members and Colonels Tony Harwood and Alas Warsap, Major Robert Newell and Drs Martin McKee. Steven Hughes and Jenny Roberts. Without thei assistance this project would not have been possible.

\section{REFERENCES}

1. CARver M. Morale in Battle - The Medical and the Military. J R Army Med Corps 1989; 135: 5-9.

2. Director of Army Training. Army Training Directives Chapter 5. Ministry of Defence 1986.

3. Chassin M. How Do We Decide Whether an Investigation or Procedure is Appropriate. In Appropriate Investigation and Treatment in Clinical Practice. Ed Hophkins A. RCP London 1988, 21-29.

4. Abramson J H. Survey Methods in Community Medicine Chapter 17. Churchill Livingstone, Edinburgh 1979.

5. Cain R L, Schwartz R R. Do We Really Need Self Aid Buddy Aid? Milit Med 1986; 151: 101-103.

6. Fogarty J P, Billingsley J L, GinnetT C W. Combat Life Saver Training: Medical Training for the Non-medic. Milit Med 1987; 152: 296-298.

7. Parker J S. Means and Limits of Life Saving Measures on the Battlefield. Medical Corps 1987; 2: 13-16.

\section{.}

